\title{
Fulminating Haemophilus Influenzae b Meningitis
}

\author{
N.E. MacDonald, D.L. Keene, A.M.R. Mackenzie, P. Humphreys, A.L. Jefferies and L.P. Ivan
}

SUMMARY: Haemophilus influenzae type b (HIb) is the most common cause of bacterial meningitis in children with a mortality rate ranging from $1.6 \%$ to $14 \%$. Most patients have a $2-3$ day history of symptoms prior to admission. A few have fulminating disease with rapid neurological deterioration. Review of 191 cases of HIb meningitis revealed a mortality rate of $2.1 \%$ but all who died had fulminating meningitis (FM). Four of six patients with FM died. FM patients had symptoms for less than 24 hours before rapid neurological deterioration with increased ICP, seizures, coma and/or respiratory arrest. Review of $10 \mathrm{FM}$ cases revealed that on admission, 5 had hypotension, 3 had thrombocytopenia, and 8 had coma. Typical CSF changes were seen in only 7 . All fatal cases died within 24 hours. Brain swelling and tonsillar herniation were found at autopsy. SDS-PAGE outer membrane protein subtyping did not show one "killer strain". Animal and autopsy data suggest that diminished CSF outflow and cerebral edema contribute to increased ICP. To improve survival of FM patients, initial treatment must (1) decrease ICP below levels impairing cerebral perfusion, (2) maintain adequate ventilation and blood pressure, and include (3) LP when stable, (4) antibiotics, and (5) close monitoring. Utilizing these principles, two FM patients survived without major sequelae.

RÉSUMÉ: L'Hémophilus influenza type b (HIb) est la cause la plus fréquente de méningite bactérienne chez l'enfant, avec une mortalité de $1.6 \%$ à $14 \%$. La plupart des patients ont une anamnèse de 2-3 jour de symptômes avant l'admission. Certains ont une maladie fulgurante avec détérioration neurologique. Chez 191 cas the méningite Hlb nous notons une mortalité de $2.1 \%$, mais tous les décès suivaient la forme fulgurante (FM). 4 des 6 patients avec FM sont morts. Les patients FM eurent des symptômes pendant moins de 24 heures puis une détérioration neurologique rapide avec hypertension intracrânienne, épilepsie, coma et/ou arrêt respiratoire. Sur 10 patients FM à l'admission, 5 avaient de l'hypotension, 3 une thrombocytopénie et 8 étaient en coma. Seuls 7 avaient des modifications typiques dans le LCR. La mort survient en déça de 24 heures. On trouva à l'autopsie un oedème cérébral et une hernie des amygdales cérébelleuses. Les données animales et l'autopsie suggèrent que le flot LCR diminué et l'oedème cérébral ont contribué à l'augmentation de la tension intracrânienne. Pour aider ces patients, le traitement initial doit (1) diminuer la tension cérébrale sous le niveau qui interfère avec la perfusion cérébrale, (2) maintenir une ventilation et une tension artérielle adéquates (3) inclure une ponction lombaire lorsque l'état est stable (4) des antibiotiques (5) et une surveillance sévère. En suivant ces principes nous avons pû sauver 2 patients FM, sans séquelles.

Can. J. Neurol. Sci. 1984; 11:78-81

Haemophilus influenzae type $b$ (HIb) meningitis is the most common type of purulent meningitis in childhood in North America. Despite the use of antimicrobial therapy, there is still a mortality which ranges from $1.6 \%$ to $14 \%$ in published reports (Santosham et al., 1979). The initial symptoms and signs of HIb meningitis are often more subtle and less fulminating than those of meningococcal or pneumococcal meningitis with most children having a two to three day history of symptoms at the time of admission (Bell and McCormick, 1981). A few patients have a fulminating course with early onset of rapid neurological deterioration, raised intracranial pressure (ICP), and early death. Although fulminating meningitis is mentioned sporadically and anecdotally in the literature, there has been no systematic study of this problem in patients with HIb meningitis.

The purpose of this paper is: (1) to report a series of ten patients with fulminating HIb meningitis to illustrate the clinical course, (2) to review the possible pathophysiological basis for the rapid neurological deterioration in fulminating meningitis, and (3) to suggest a treatment plan for the early management of these patients.

\section{SUBJECTS AND METhodS}

The charts of all patients with bacteriologically proven $\mathrm{HIb}$ meningitis treated at the Children's Hospital of Eastern Ontario between January 1975 and October 1982 were reviewed. The case definition of fulminating HIb meningitis required bacteriologically proven $\mathrm{HIb}$ CSF infection, a clinical course of less than 24 hours between the onset of any symptoms or signs of infection and the occurrence of severe neurological deterioration with seizures, coma, and/or respiratory arrest.

In addition to the six FM cases from the Children's Hospital of Eastern Ontario, four other case histories of children with fulminating Hlb meningitis were evaluated: one from the Children's Hospital in Vancouver, two patients from the Montreal Children's Hospital, and a case from Strong Memorial Hospital, Rochester, New York.

The outer membrane protein subtypes of the HIb isolates from 5 of 7 fatal cases of fulminating meningitis were analyzed using a previously described subtyping system (Loeb and Smith, 1980).

From the Departments of Pediatrics and Surgery (Neurosurgery), Children's Hospital of Eastern Ontario, Ottawa, Ontario

Presented in part at the Canadian Paediatric Society Meeting. Quebec City. Quebec, 1983

Received June 2, 1983. Accepted in revised form November 25. 1983

Reprint requests to: N.E. MacDonald, M.D., Head, Infectious Disease Service, Children's Hospital of Eastern Ontario, 401 Smyth Road, Ottawa. Ontario K1H 8 LI 


\section{RESULTS}

Survey of 191 patients with bacteriologically proven HIb meningitis at the Children's Hospital of Eastern Ontario revealed six cases of fulminating meningitis between January 1975 and October 1982. The overall mortality due to HIb meningitis was $2.1 \%$ but the four patients that died all had fulminating disease. The mortality rate for this presentation was $67 \%$ : four of the six patients died.

Review of the clinical presentation of fulminating HIb meningitis for these six patients and the four additional cases revealed that the mean age was 23 months (median age 9 months; range 4 month-5 years). There were 6 males and 4 females. By definition, all had a short time interval between onset of any signs or symptoms of infection and severe neurological deterioration. The mean duration of illness prior to admission was only 12 hours (range 4-24 hours). In these 10 patients, fever greater than $38.5^{\circ} \mathrm{C}$ ( 10 patients), irritability (7), coryza (5), and vomiting (5) were common presenting complaints. In addition, 6 patients had seizures before admission, 3 presented in coma, and 3 had had respiratory arrests at home. Signs of raised ICP were evident in 9 of the 10 patients on admission and included abnormal pupils ( 8 patients) abnormal fundoscopic examinations ( 7 ), coma and abnormal motor function (8). Five patients were hypotensive. Only two patients had neck stiffness or positive Kernig's or Brudzinski's signs.

Comparison of the initial laboratory results for the fatal and non-fatal FM cases did not reveal any differences between the two groups. The mean white blood cell count on admission was $6900 \mathrm{cells} / \mathrm{cu} \mathrm{mm}$ (range 3200-15,500). The neutrophil/band count ranged from $9 \%$ of 3,200 cells $/ \mathrm{cu} \mathrm{mm}$ to $78 \%$ of $15,500 \mathrm{cells} / \mathrm{cu}$ $\mathrm{mm}$. Four of the 10 patients were mildly anemic on admission with a hemoglobin of less than $10.7 \mathrm{gm} / \mathrm{dl}$. Three patients also had thrombocytopenia and two were hyponatremic $(\mathrm{Na}+126$ $\mathrm{mEq} / 1,124 \mathrm{mEq} / \mathrm{l})$. The initial CSF examination was abnormal and helped to make the diagnosis in most cases. However, two children had CSF white cell counts of only 8 and 15 with only minimal changes in glucose and protein and no organisms on gram stain. Both grew HIb on culture and both children died within 12 hours with severe cerebral edema. In 3 of the 7 fatal cases, ampicillin resistant HIb was grown from the CSF. All patients initially received ampicillin and chloramphenicol pending culture results.

Seven of these 10 children with fulminating meningitis died, all within 24 hours of admission despite early antibiotic therapy. At autopsy, each of the 7 had cerebral edema determined by brain weight, purulent exudate over the convexities of the brain, and cerebellar tonsillar herniation. In addition, 5 had anoxic changes in the brain stem and 3 had areas of focal cortical necrosis of the brain.

Three children survived; one with severe neurological impairment including marked mental retardation, spastic quadriplegia, blindness, and deafness. In contrast, the two other survivors have only minimum sequelae at one year follow up. Both of these children received very early treatment aimed at maintaining an adequate cerebral perfusion pressure by decreasing the elevated ICP and supporting the arterial blood pressure. This is in contrast to the other patients where initial attention was focused on the lumbar puncture and antibiotic therapy with some delay in recognition and treatment of the increased ICP. Two illustrative cases, one fatal and one non fatal, are described below.
Case 1: In July 1978. this previously healthy four year old girl began to complain of a sore throat twelve hours prior to admission. Six hours later she was seen by her pediatrician who noted a low grade fever. enlarged hyperemic tonsils. and mildly increased cervical lymphadenopathy. Although a prescription for penicillin was filled, the child did not receive any medication because of the onset of vomiting with lethargy and increased irritability. Following a five minute generalized seizure she was brought to the Emergency Department at the Children's Hospital of Eastern Ontario.

On admission she was febrile $\left(38.5^{\circ} \mathrm{C}\right)$ and comatose. She had several short generalized seizures in the Emergency Room. Her blood pressure was $120 / 70$, pulse 90 , and respiratory rate $30 /$ minute. There was slight neck stiffness but Kernig's and Brudzinski's signs were negative. The pupils were equal, but only sluggishly reactive, the fundi were unremarkable, as were the examinations of the chest, abdomen, and cardiovascular systems. Her deep tendon reflexes were depressed and her plantar reflexes were equivocal.

Initial laboratory investigations revealed a white blood cell count of 15.500 with $78 \%$ neutrophils/bands. Her hemoglobin was $12.8 \mathrm{gm} / \mathrm{dl}$. Both the platelet count and serum sodium were normal. Her CSF had 5000 white blood cells/cu $\mathrm{mm}$ with $88 \%$ neutrophils. The CSF glucose was $10 \mathrm{mg} / \mathrm{dl}$ and the protein was $300 \mathrm{mg} / \mathrm{dl}$. Gram negative bacilli were seen on the smear. Emergency room therapy included diazepam and phenobarbital for seizure control and then intravenous ampicillin and chloramphenicol prior to transfer to the Intensive Care Unit. Within six hours of admission she had abrupt respiratory failure and her right pupil became fixed and dilated. She was resuscitated. intubated. hyperventilated, and received mannitol and dexamethasone. Despite this, 12 hours after admission, she remained areflexic with fixed dilated pupils, had electrocerebral silence, and no cerebral blood flow by cerebral angiogram. Ventilatory support was discontinued.

At autopsy the brain was severely swollen with bilateral uncal and tonsillar herniation. The meninges were cloudy gray and heavily infiltrated by neutrophils. There were several areas of acute focal cerebritis. Cultures of her CSF taken on admission were positive for $\mathrm{HIb}$ sensitive to ampicillin.

Case 2: On the evening prior to admission. in July 1981 , a previously healthy 20 month old boy was noted to have a low grade fever and he vomited once before falling asleep. In the morning he was comatose, cool, pale, and gray with heavy irregular respirations. He was brought immediately to the Children's Hospital of Eastern Ontario where he was noted to be febrile $\left(38.5^{\circ} \mathrm{C}\right)$, deeply comatose, unresponsive to pain with Cheyne-Stokes respiration and hypotensive. Examination of the fundi showed venous distension and no pulsation. The pupils were equal and reactive to light. Petechiae were noted on the trunk and limbs. Initial laboratory results indicated a white cell count of 7,900 with $67 \%$ neutrophils/bands. The hemoglobin was $10.7 \mathrm{gm} / \mathrm{dl}$ and the platelet count was 80,000 . The serum sodium was normal. The CSF had 275 white blood cells/cu $\mathrm{mm}$ with $83 \%$ neutrophils with a glucose of $5 \mathrm{mg} / \mathrm{dl}$ and a protein of $89 \mathrm{mg} / \mathrm{dl}$. Gram negative bacilli were seen on the smear. In addition, on admission a computerized axial tomography scan of the head showed a small area of decreased density adjacent to the tip of the left temporal horn and early cerebral edema.

Initial treatment included fluids to maintain an adequate blood pressure (eg. Ringer's lactate, fresh frozen plasma, blood) titrated by using a central venous pressure monitor: mannitol. dexamethasone, hyperventilation, and barbiturate coma to treat his increased ICP. The ICP was closely followed with a continuous $I C P$ monitor. He also received ampicillin and chloramphenicol to treat his HIb meningitis. and phenytoin and phenobarbital for the right sided focal seizures which started shortly after admission. When the CSF grew HIb sensitive to ampicillin, the chloramphenicol was discontinued.

Complications included acute renal failure with oliguria, disseminated intravascular coagulopathy with thrombocytopenia and increased fibrogen degradation products, metabolic acidosis, and infarction of the tips of four toes. Despite the severity of the illness, the patient survived. Three weeks later, at the time of discharge, the deficits included a moderate right hemiparesis, decreased vision and slightly decreased hearing. Within three months of discharge, vision, hearing, and speech had returned to normal but the moderate right hemiparesis persisted. At one year follow up examination, the patient was an alert active three year old with only a very mild right hemiparesis. Vision, hearing, and psychological assessments were normal. 


\section{Outer Membrane Protein Subtypes of HIb in FM}

Analysis of the outer membrane protein subtypes of the Hlb isolates from patients $1-5$ demonstrated that the isolates from patients 1-3 belonged to SDS-PAGE subtype 1, which corresponds to subtype IL of the Granoff system (Barenkempt et al., 1981). The strain from patient 4 was SDS-PAGE subtype 2 or Granoff subtype 5, while the strain from patient 5 was Granoff subtype $1 \mathrm{H}$.

\section{Discussion}

As these ten patients illustrate, many of the early presenting symptoms in children with fulminating HIb meningitis are not different from the nonspecific symptoms commonly seen in nonfulminating HIb meningitis, ie. fever, irritability, and coryza. It is important to note that only two of the 10 patients had neck stiffness or positive Kernig's or Brudzinski's signs. Thus the diagnosis of meningitis may not always be considered at the time of presentation. However, all of these children were very ill when first seen. Six had seizures prior to admission, three came in with coma, and three had had respiratory arrests prior to arrival at the hospital. Signs of raised intracranial pressure were evident in 9 of the 10 patients on admission.

In contrast to the nonfulminating meningitis patients, within 24 hours there was rapid deterioration in the neurological status with increased ICP, seizure, coma, and/or respiratory arrest. This occurred even in the five infants with widely open fontanelles. Even at this stage only minimal changes were present in the CSF of two patients making the early diagnosis of meningitis more difficult. Without aggressive treatment of increased intracranial pressure, this condition was rapidly fatal with brain death in less than 24 hours despite antibiotic therapy. In all seven patients that died, there was evidence of increased ICP with brain swelling, purulent exudate over the convexities and cerebellar tonsillar herniation. Although fulminating HIb meningitis does not appear to be a common problem (only 6 of 191 cases $(3.1 \%$ ) of HIb meningitis at the Children's Hospital of Eastern Ontario), the four fatal cases represented the total number of death due to HIb meningitis during that entire time.

The pathophysiology of the increased ICP in fulminating HIb meningitis is not completely understood. From the review of these patients and the data from animal models (Smith et al., 1982; Scheld et al., 1980; Johnson et al., 1978; Sharbo et al., 1968), the two most likely mechanisms contributing to decreased intracranial compliance and rapidly increasing ICP are (1) decreased or obstructed cerebrospinal fluid (CSF) outflow due to arachnoid villus dysfunction and (2) cerebral edema secondary to cerebral ischemia and hypoxia due to cortical venous thrombosis. Our autopsy results, as well as one of the cases reported by Horwitz and colleagues (1980) and the recent study by Goitein and Tamir (1983) suggest that cerebral edema may be the major contributing factor in increased ICP in fulminating HIb meningitis. Hypoxia may not be the only factor contributing to cerebral edema. Chan and Fishman (1978) have shown that brain slices become edematous in the presence of fractions of normal neutrophil membranes. This process may be relevant in some cases of fulminating HIb meningitis with prolonged increased ICP and cerebral edema. However, the early rapid rise cannot be due to this mechanism alone since two FM patients had only 8 and 15 CSF white blood cells/cu mm at the time of the marked elevation in ICP. Inappropriate antidiuretic hormone secretion with fluid retention and exacerbation of cerebral edema has been noted in children with bacterial meningitis (Kaplan and Feigin, 1978). The role that antidiuretic hormone plays in the rapid early increase in ICP in fulminating $\mathrm{HIb}$ meningitis is unclear; however, two of the seven FM patients reported here had low serum sodium concentrations $(126 \mathrm{mEq} / 1$ and 124 $\mathrm{mEq} / 1$ ) on admission, less than 12 hours after onset of any signs and symptoms of infection.

After reviewing the data from these fulminating $\mathrm{Hlb}$ meningitis patients, the possibility of a "killer" strain of HIb was considered. Analysis of isolates from five fatal cases revealed three SDSPAGE subtypes based on the major outer membrane protein. with the Granoff subtype 1L accounting for three of the five strains $(60 \%)$. When Granoff and colleagues analyzed 256 strains from 22 states, $7 \%$ were subtype $\mathrm{IL}$ and $39 \%$ were subtype $\mathrm{IH}$ (Barenkempt et al., 1981). Therefore subtype IL appears to be disproportionately represented in this series of fulminating HIb meningitis patients. However, the sample is very small and the distribution of subtypes can vary geographically. Therefore it is still unclear whether there is a common "killer" factor in some HIb which increased the probability of fulminating meningitis occurring or whether these strains are simply "typical" local HIb strains which cause fulminating meningitis in particularly susceptible hosts.

During the past ten years, most of the literature on the management of acute bacterial meningitis has primarily focused on appropriate choice and delivery of antibiotics. However, antibiotics take hours to exert their bactericidal effects (Mackenzie, 1979; Turk, 1977) and in the interim acutely raised ICP and inadequate cerebral perfusion pressure may kill or permanently damage these patients. Furthermore, studies of fluid filled compartments with increased intraluminal pressure due to outflow obstruction, eg. the gall bladder, have shown that there may be minimal penetration of intravenously administered antibiotics which are normally present in high concentrations (Papachristodoulou et al., 1978; Mortimer et al., 1969). By analogy, raised ICP with increased CSF pressure due to outflow obstruction may diminish the antibiotic flux across the choroid plexus into the CSF and hence reduce the efficacy of treatment. Antibiotic therapy may be further undermined if the cerebral perfusion pressure is critically reduced due to a marked increase in ICP and/or hypotension and shock. In either case, intravenous antibiotics cannot reach the CSF. For these reasons, while not belittling the obvious importance of early antibiotic therapy, the treatment of raised ICP and maintaining an adequate mean arterial pressure are the major priorities in the early management of fulminating meningitis in order to ensure maximal survival with minimal morbidity.

The common methods to treat patients with acutely raised ICP not due to meningitis include (1) intubation and mechanical hyperventilation, (2) hypertonic solutions such as mannitol, (3) high dose steroids, (4) barbiturate coma, (5) hypothermia, and if all these fail, (6) craniotomy (Hahn, 1980). Unfortunately, some of these techniques may have adverse effects in infected patients. For example, using an experimental piglet model, Gillis and colleagues (1982) have recently demonstrated that the number of circulating neutrophils falls during hypothermia. Neuwelt et al. (1982) noted lymphocyte suppression during barbiturate coma which was more pronounced with thiopental then with phenobarbital. In addition steroids are well known to depress resistance to bacterial infection (Perper et al., 1974; 
Vernon-Roberts, 1972; Rinehart, 1975). How significant any of these factors are in exacerbating meningitis is unclear. Until more data are available, we would recommend aggressive treatment of increased ICP starting with hyperventilation and mannitol. Fluid restriction is also important in the treatment of inappropriate antidiuretic hormone but care must be taken to maintain a peripheral blood pressure that is adequate to sustain cerebral perfusion.

Patients with fulminating meningitis can best be managed in an intensive care setting since the clinical course can change very rapidly with abrupt deterioration with little or no warning. Continuous monitoring of the mean arterial blood pressure and ICP enables early diagnosis and rapid treatment if the cerebral perfusion pressure falls below critical levels. Intracranial pressure monitoring systems are valuable aids in the management of these FM patients. In young infants with open fontanelles, fontanelle monitors may be more appropriate.

Effective chemotherapy of bacterial meningitis depends upon an accurate diagnosis which is determined by examination and culture of CSF. Lumbar puncture has certain risks, especially in a patient with increased ICP. A useful tool in evaluating these patients prior to lumbar puncture is the Glasgow Coma Scoring System (Teasdale and Jennett, 1974; Jennett et al., 1977). In patients with a score of less than 7 , acute brain resuscitative measures should take precedence over immediate lumbar puncture. These include the management of shock and early elective intubation if there is any evidence of respiratory compromise. If necessary, intravenous mannitol should then be given to help control the ICP. If the patient is stable, the lumbar puncture may then be performed twenty minutes after the mannitol infusion preferably by a well experienced physician using a small gauge needle to collect the minimum amount of CSF necessary for diagnosis. Since over half the patients with Hlb meningitis have positive blood cultures (Smith et al., 1982), in some very unstable patients, one may elect to take a blood culture, start antibiotics, and postpone the lumbar puncture until the ICP is more controlled. Due to the continued risk of herniation following the lumbar puncture, close observation by skilled medical staff and rapid transfer to an appropriate intensive care setting is necessary. In these severely ill patients, computerized tomography of the head may be a helpful aid in ruling out other causes of increased intracranial pressure; however, appropriate medical management of the patient must never be delayed while waiting for the scan.

Although cerebral edema and raised ICP do not appear to be as acute a clinical problem in the more common non-fulminating HIb meningitis patients, pathological studies are not available on survivors to verify whether or not these factors play a role in the development of sequelae in these patients. Early identification and active treatment of increased ICP and maintenance of an adequate perfusion pressure might reduce the incidence of serious sequelae in some of these patients.

\section{ACKNOWLEDGEMENTS}

The authors wish to thank Drs. D. Scheifele, D. Clogg, and K. Powell for kindly providing additional patients with acute fulminating meningit is and Dr. M. Loeb for analysis of the outer membrane protein and Dr. Arnold Smith for his helpful comments.

\section{REFERENCES}

Barenkempt. S.J.. Munson. R.S., Granoff. D.M. (1981). Subtyping of Haemophilus influenzae type $b$ isolates by outer membrane protein profiles. J Infect Dis 143:668-676.

Bell, W.E.. McCormick. W.F.. (eds.). (1981). Haemophilus influenzae meningitis. In: Neurologic Infections in Children. 2nd Edition. Major Problems in Clinical Pediatrics, Volume 12: W.B. Saunders Company. pp. 134-154.

Chan, P.H.. Fishman. R. (1978). Brain edema: Induction in cortical slices by polyunsaturated fatty acids. Science $201: 358-360$.

Gillis. J.. Bohn. D., Barker. C.. et al. (1982). Blood neutrophil alterations associated with induced hypothermia. 59th Annual Canadian Pediatric Society Meeting: London, Ontario Canada, Abstract 14, page 66.

Goitein, K.J., Tamir 1. (1983). Cerebral perfusion pressure in central nervous system infections in infancy and childhood. J. Pediatr. 103:40-43.

Hahn, J.F. (1980). Cerebral edema and neurointesive care. Ped. Clin. N. Amer. 27:587.592.

Horwitz, S.J., Boxerbaum, B.. O'Bell, J. (1980). Cerebral herniation in bacterial meningitis in childhood. Ann. Neurol. 7:524-528.

Jennett, B.. Teasdale. G., Galbraith. S., et al. (1977). Severe head injuries in three countries. J. Neurol. Neurosurg. Psych. 40:291-298.

Johnson, R.N., Maffeo. C.J., Dacey, R.G., et al. (1978). Mechanism for intracranial hypertension during experimental subarachnoid hemorrhage: acute malfunction of arachnoid villi by components of plasma. Trans. Am. Neurol. Assoc. 103:138-142.

Kaplan. S.L.. Feigin, R.D. (1978). The syndrome of inappropriate secretion of antidiuretic hormone in children with bacterial meningitis. J. Pediatr. 92:758-761.

Loeb, M.R., Smith, D.H. (1980). Outer membrane protein composition in disease isolates of Haemophilus influenzae: Pathogenic and epidemiological implications. Infect. Immun. 30:709-717.

Mackenzie, A.M.R. (1979). Combined action of chloramphenicol and ampicillin on Haemophilus influenzae. J. Antimicrob. Agents Chemother. 5:693-698.

Mortimer, P.R., Mackie, D. B., Haynes, S. (1969). Ampicillin levels in human bile in the presence of biliary tract disease. Br. Med. J. 3: 88-89.

Neuwelt, E.A., Kikuchi. K., Hill, S.A., et al. (1982). Barbiturate inhibition of lymphocyte function. Differing effects of various barbituates used to induce coma. J. Neurosurg. 56:254-259.

Papachristodoulou, A.J., Mackenzie, A., Norman, J., et al. (1978). Single dose Cephazolin prophylaxis in biliary tract surgery. J. Royal College of Surgeons of Edinburgh 23:178-183.

Perper, R.J., Chinea, G., and Oronsky, A.L. (1974). Leukocyte chemotaxis in vivo. II. Analysis of the selective inhibition of neutrophil or mononuclear cell accumulation. J. Lab. Clin. Med. 84:394-406.

Rinehart, J.J., Sagone, A.L., Balcerzak, S.P., et al. (1975). Effects of corticosteroid therapy on human monocyte function. N. Engl. J. Med. 292:236-241.

Santosham, M., Kallman, C.H., Neff, J.M., et al. (1979). Absence of increasing incidence of meningitis caused by Haemophilus influenzae type b. J. Infect. Dis 140:1009-1012.

Scheld, W.M., Dacey. R.G., Winn, H.R., et al. (1980). CSF outflow resistance in rabbits with experimental meningitis. Alterations with penicillin and methylprednisolone. J. Clin. Invest. 66:243-253.

Sharbo, A.L., Maxwell, D.S., (1968). Electron microscopic observations on the fate of particulate matter in the cerebrospinal fluid. J. Neursurg. 29:464-474

Smith, A.L., Daum, R.S., Scheifele, D., et al. (1982). Pathogenesis of Haemophilus influenzae meningitis, Section III. Haemophilus Influenzae Meningitis. In: Haemophilus Influenzae. Sell, S.H., Wright, P.F. (eds.), Elsever Science Publishing Co. Inc. pp. 89-109.

Teasdale, G., Jennett, B. (1974). Assessment of coma and impaired consciousness. Lancet 2:81-84.

Turk, D.C. (1977). A comparison of chloramphenicol and ampicillin as bactericidal agents for $\mathrm{H}$. influenzae type b. J. Med. Microbiol. 10:127-131.

Vernon-Roberts, B. (1972). The Macrophage. Cambridge: University Press, Great Britain, Vol. 4-5:92-119. 